\title{
STUDY ON PSYCHOSOCIAL STRESSORS AND PSYCHIATRY MORBIDITY IN ACUTE MYOCARDIAL INFARCTION: A QUANTITATIVE STUDY
}

\author{
Mohamed Ilyas Rahamathulla Musthafa Kamal Batcha', Alexander Gnanadurai William James², Arunkumar Annamalai ${ }^{3}$ \\ ${ }^{1}$ Assistant Professor, Department of Psychiatry, Government Stanley Medical College, Chennai. \\ 2 Professor, Department of Psychiatry, Government Stanley Medical College, Chennai. \\ ${ }^{3}$ Research Officer, Department of Psychiatry, Government Stanley Medical College, Chennai.
}

\begin{tabular}{l}
\hline ABSTRACT \\
\hline BACKGROUND \\
Numerous biological, environmental, behavioural, and sociocultural variables interact in its aetiology and pathogenesis of \\
Coronary Heart Disease. It can be seen as a disorder of lifestyle and many of its aetiologic agents are potentially modifiable \\
particularly life stressors.
\end{tabular}

AIM

We aimed 1. To compare the occurrence of stressful life events among myocardial infarction patients with non-myocardial infarction patients with diabetes mellitus as control group who are with same age and sex. 2. To assess the level of psychiatric morbidity in the post myocardial infarction period.

\section{MATERIALS AND METHODS}

The study was conducted in the intermediate care unit, Department of Cardiology, of tertiary care hospital. Thirty consecutive patients admitted who satisfied the inclusion criteria were included in the study. Thirty randomly selected patients were taken as controls. Both the patients and controls were administered the following tools: Presumptive Stressful Life Events Scale (PSLES), Socio-Economic Status scale (SES), Hospital anxiety and depression scale and ICD 10 criteria for depressive episode.

\section{RESULTS}

The clinical variable, blood pressure, and blood glucose level showed statistically significant level in myocardial infarction group. Alcohol drinking and smoking did not have any statistical significance. Presumptive stressful life events in the past 12 months are statistically significant.

\section{CONCLUSION}

Patients who developed myocardial infarction have more stressful life events in the preceding 12 months. Both depression and anxiety were significantly more in myocardial infarction than the controls. Further research requires samples representing all socioeconomic status to have a clear picture of the association of the biological and socioeconomic risk factors in coronary heart disease.

\section{KEYWORDS}

Myocardial Infarction, Psychiatric Morbidity, Stressful Life Events.

HOW TO CITE THIS ARTICLE: Batcha MIRMK, James AGW, Annamalai A. Study on psychosocial stressors and psychiatry morbidity in acute myocardial infarction: a quantitative study. J. Evolution Med. Dent. Sci. 2016;5(52):3445-3451, D0I: $10.14260 /$ jemds/2016/795

\section{INTRODUCTION}

Among the cardiovascular diseases, ischaemic heart disease (myocardial infarction) is responsible for one third of all deaths, in men between the ages of 45 to 64 in the industrialized nations (WHO, 1975). ${ }^{1}$ In India, especially in the urban population, the prevalence rate of Coronary Heart Disease approaches that found in the west. Chadha and Radhakrishna (1990) carried out an epidemiological study on an urban population and report a rate of 96.7 per $1000 .{ }^{2}$

The prevalence of Coronary Heart Disease in rural population in India is low (Jatoo et al, 1988). ${ }^{3}$ There is a strong evidence to suggest that interplay of personality

Financial or Other, Competing Interest: None.

Submission 14-05-2016, Peer Review 08-06-2016,

Acceptance 14-06-2016, Published 30-06-2016.

Corresponding Author:

Dr. Alexander Gnanadurai William James,

Professor, Department of Psychiatry,

Government Stanley Medical College, Chennai.

E-mail:drdralex@gmail.com

DOI: $10.14260 /$ jemds/2016/795 characteristics with the environmental milieu plays a role in an individual's predisposition to coronary heart disease and large body of research has already been undertaken in this area (Rosenman and Friedman, 1960). 4

Numerous biological, environmental, behavioural, and socio-cultural variables interact in its aetiology and pathogenesis (Kannel, 1983). ${ }^{5}$ Coronary Heart Disease can be seen as a disorder of life style and many of its aetiologic agents are potentially modifiable. As a result, cardiovascular disorders have become one of the most researched topics and new area for research in psychosocial and behavioural cultural factors (Finegold et al, 2013). ${ }^{6}$ A broadened search for mechanisms and influences contributing to Coronary Heart Disease had led to the examination of biological risk factors, social variables, psychological factors (e.g. Type A behaviour) and environmental characteristics (e.g. Life stressors).

The type A or coronary prone behaviour pattern was first fully described and measured by Friedman and Rosenman (1959). ${ }^{7}$ Evidence supportive of Type A Behaviour Pattern as a Coronary Heart Disease risk factor has resulted from two 
major prospective studies of initially healthy individuals. The Western Collaborative Group Study (WCGS) began in 1960 and examined approximately 3200 initially healthy men for 8.5 years. The final report showed that those men assessed as type A by a structured interview were more than twice as likely to develop clinical Coronary Heart Disease than those assessed as type B (Rosenman et al, 1975). ${ }^{8}$ In the Framingham's heart study, a psychosocial questionnaire was administered, from which the Framingham type A scale was derived. High scores on this became an independent predictor of Coronary Heart Disease after 8 years (Haynes et al, 1980). ${ }^{9}$

The Belgian-French heart study of initially healthy men, which used a self-rating scale designed by Bortner to measure type A, again found that the incidence of Coronary Heart Disease associated with Type A Behavioural pattern (BelgianFrench Pooling Project, 1984). ${ }^{10}$ Type A assessed by Bortner questionnaire has been found to be associated with coronary Heart Disease in a study among men in the U.K. (Heller, 1979). ${ }^{11}$ Final results revealed no relation between Type $A$ Behavioural Pattern and any clinical manifestation of coronary heart disease (Shekelle et al, 1985). ${ }^{12}$

In India, Bhatia et al (1990).13 studied 50 patients with Coronary Heart Disease and 50 normal controls, found Type A Behavioural Pattern in $72 \%$ of patients as compared to only $16 \%$ in the control group. Mahendru et al (1976). ${ }^{14}$ conducted a study on patients admitted in medical wards, Lucknow, for coronary heart disease. The study included seventy six patients of varying degrees of myocardial ischaemia. In $61.8 \%$ presence of emotional stress of sufficient intensity prior to the onset of coronary heart disease was demonstrated. The most frequent area of disturbance was maladjustment in the family (36.9\%), Severe financial stress $(21.0 \%)$, Job difficulties (19.7\%), Heavy loss in business (19.7\%), Heavy debts (15.7\%) Martial disharmony (9.2\%), Death of wife (9.2\%) Law suits and court appearances (7.9\%), Death of children (7.9\%), Recent death of parents (7.9\%), Any chronic (or) disabling illness in the patient (6.6\%), Death of any other close family member (5.3\%), and any disability or chronic illness in close family member $(3.9 \%)$. One half of the patients reacted to heart attacks with depression, while $31.6 \%$ cases showed anxiety following attacks and the rest denied the existence of psychological repercussions.

Rama Reddy (1987).15 conducted a study on stressful life events preceding the onset of myocardial infarction and the psychological reaction occurring in the hospital following myocardial infarction. Patients experience more stressful events prior to onset of myocardial infarction. Emotional disturbances like anxiety and depression were found following infarction. Recovery depends on the social adjustment. Those who experienced more stressful events before the onset of myocardial infarction showed more anxiety and depression.

Bhatia et al, (1990).13 studied the relationship between type A behaviour and stressful life events and its sequelae. Patients experienced higher number of stressful events in the year before the attack. Type A and Type B patients developed myocardial infarction. Both groups face higher life events and there was no significant difference in life changes during the past one year between Type A and Type B individuals. The mean anxiety and depression score in patients was high and also showed statistically significant improvement with passage of time.
Andrews (1981). ${ }^{16}$ conducted study of life events and psychological symptoms found that the occurrence of the major life events would increase the risk of illness between 2 and 7 times depending on the severity of the events and type of illness. There is an increase in risk for anxiety and depression.

In the study of Krantz, Kop, and Santiago (1996). ${ }^{17}$ it was found that acute stress triggers myocardial infarction and sudden death in vulnerable individuals through its action on central and autonomic nervous system. Shapiro (1996) studied psychiatric aspects of cardiovascular disease. ${ }^{18}$ The psychological factors in the development and progression of cardiac disease and psychiatric problems that arises in patients with cardiac illness was studied. The psychological factors are Type A behaviour pattern and stressful life circumstances. Depression is a common problem following myocardial infarction. Major depression is $20 \%$ in the post myocardial infarction period.

Paykel (1974) studied the relationship between life events and depression and reported that neurotic depression is more common than psychotic or endogenous depression. ${ }^{19}$ Jenkins (1976) reported anxiety, depression have been frequently associated with Coronary Heart Disease. ${ }^{20}$ Forrester et al (1992) reported major depressive syndromes were present in $19 \%$ of patients following acute myocardial infarction. ${ }^{21}$ Several well conducted studies reported no relationship between environmental stress and myocardial infarction, conceptualized as life change and risk of coronary heart disease (Theorell et al, 1972). ${ }^{22}$ This may be due in part to the inappropriateness of life changes as a dimension of judging the impact of life event.

Lundberg et al (1975) were unable to distinguish between patients with coronary heart disease and controls on the basis of a life change index, but the use of an index based on the event to which subjects personally rated items in a life event inventory. ${ }^{23}$ Ibrahim et al (1974). ${ }^{24}$ reported the reduction of coronary heart disease by $65 \%$ in one year follow up and subsequent studies by Rahe et al (1979). ${ }^{25}$ Ruberman et al (1984). ${ }^{26}$ confirmed these effects. Merz et al (2002) has found the $50 \%$ of reduction cardiac events in the intervention group in their study. 27

\section{The Aims of the Study are}

1. To compare the occurrence of stressful life events among myocardial infarction patients and non-myocardial infarction patients with diabetes mellitus as control group who are with same age and sex.

2. To assess the level of psychiatric morbidity in the post myocardial infarction period.

\section{METHODS}

The study was conducted in the intermediate care unit, Department of Cardiology, of a tertiary care hospital. The study was approved by ethical committee of the hospital and all the consenting patients were recruited only after signing the informed consent form. Thirty consecutive inpatients who satisfied the following criteria were included in the study. The inclusion criteria are: 1 . Patients should have been admitted as an inpatient in the intensive care unit with the clinical and electrocardiogram (ECG) confirmation of myocardial infarction; 2 . The present episode should be the first episode of myocardial infarction; 3. Patient should have fairly 
recovered from myocardial infarction and advised as fit for interview by the cardiologists and shifted to intermediate care unit and 4. Patients who were willing to co-operate for interview were included in the study. The exclusion criteria are: 1 . Other than myocardial infarction, patients experiencing signs of angina pectoris, unstable angina etc. 2. Patients with previous psychiatric, psychosomatic illnesses. 3. Patients with any other chronic physical illness, which is not comorbid with myocardial infarction. 4. Patients with diabetes mellitus, who developed myocardial infarction. 5. Those patients who have previously undergone coronary bypass procedure and now developing first episode of myocardial infarction.

Thirty age and sex matched diabetic patients without myocardial infarction were taken as controls. Both the patients and controls were administered the following tools: Presumptive Stressful Life Events Scale (PSLES), Socio Economic Status Scale (SES), Hospital Anxiety and Depression Scale, and ICD 10 criteria for depressive episode.

\section{Presumptive Stressful Life Events Scale (PSLES- Gurmeet Singh et al 1984). ${ }^{28}$}

Presumptive stressful life events designed for use in Indian population. It was devised based on Holmes and Rahe's Social Readjustment Rating Schedule (SRRS). ${ }^{29}$ because many items in social readjustment rating schedule were found to be not suitable for Indian population. This is a 51 items scale developed by Gurmeet Singh et al in 1984 for particular application to the Indian culture. ${ }^{28}$

\section{Hospital Anxiety and Depression Scale}

In this scale, Zigmond and Snaith (1983) attempted to overcome a problem in the use of symptom rating scale in hospital populations. ${ }^{30}$ The Hospital Anxiety and Depression scale was found to be a reliable instrument for detecting states of depression and anxiety in the setting of a hospital medical inpatient/outpatient clinic (Zigmond and Snaith, 1983). ${ }^{30}$

\section{Socio Economic Status Scale (SES) (Kuppuswamy, 2012). . $^{31}$}

Socio economic status consists of scores on 3 variables (viz. Education, Occupation, and Income) on the basis of a 10-point scale. It consists of 10 categories of socio economic status ranging from highest to the lowest. The 10 point scale consists of 200 scores with equal class intervals. The categories are being grouped into 5 social class viz., very high, high upper middle, lower middle, and very low. The inter-rater reliability is found to be high $(\mathrm{R}=0.9)$.
The following statistical methods were used in the study; parametric tests like simple mean, standard deviation, students' ' $t$ ' test. Karl Pearson's coefficient of correlation was used. Non-parametric tests using chi square was also used for qualitative variables.

\section{RESULTS}

Table I shows the distribution of myocardial infarction and diabetes mellitus patients with regard to age. The results show that $56.67 \%$ of myocardial infarction group lies between 25 to 55 years and $43.33 \%$ of myocardial infarction patients lie above 55 years. In the diabetes mellitus group, the results show that $53.33 \%$ of patients were between 25 to 55 years and $46.67 \%$ of patients were above 55 years. This is statistically not significant. Hence, the sample and the control were matched according to age. Other socio demographic variable, sex, marital status, literacy, domicile are well matched with control group. The clinical variable, blood pressure, and blood glucose level showed statistically significant level in myocardial infarction group. Alcohol drinking and smoking did not have any statistical significance. Table-4 shows that, in myocardial infarction group, 13 patients had 2 or less number of presumptive stressful life events in the past 12 months, and 17 patients had more than 2 presumptive stressful life even in the past 12 months, whereas in diabetes mellitus group, 24 patients had 2 or less number of presumptive stressful life events in the past 12 months, and 6 patients had more than 2 presumptive life events in the past 12 months. This difference is statistically significant. Table -5 shows that in myocardial infarction group, 9 patients were having 110 or less of total score of presumptive like events in the past 12 months. Whereas, 21 patients had the score of more than 110 in the preceding 12 months. In diabetes mellitus group again 25 patients had the score of 110 or less in the presumptive life events score in the preceding 12 months and 5 patients had score of more than 110 in the preceding 12 months. This difference is again statistically significant. Depressive and anxiety score shows statistical significance.

Table 10 shows that the total number of life events in the preceding 12 months of those myocardial infarction patients who are having hypertension is statistically significant when compared to those myocardial infarction patients who are not having hypertension. Inter correlation matrix shows (Table 11) that in myocardial infarction group, the life events positively correlate with anxiety, systolic blood pressure positively correlates with diastolic blood pressure, life events, and anxiety, whereas diastolic blood pressure positively correlated with blood glucose, life events, and anxiety, the blood glucose positively correlates with life events and anxiety.

\section{DATA ANALYSIS}

\begin{tabular}{|c|c|c|c|c|c|c|}
\hline \multirow[t]{2}{*}{ Sl. No. } & \multirow[t]{2}{*}{ Variables } & \multicolumn{2}{|c|}{$\begin{array}{c}\text { Sample Myocardial } \\
\text { Infarction } \mathbf{n}=\mathbf{3 0}\end{array}$} & \multicolumn{2}{|c|}{$\begin{array}{c}\text { Control } \\
\text { Diabetes Mellitus } \mathrm{n}=\mathbf{3 0}\end{array}$} & \multirow{2}{*}{$\begin{array}{l}\text { Statistical } \\
\text { Significant }\end{array}$} \\
\hline & & $\mathbf{n}$ & $\%$ & $\mathbf{n}$ & $\%$ & \\
\hline 1 & $\begin{array}{l}\text { Age in years } \\
\text { a. } \quad<25 \\
\text { b. } 26-55 \\
\text { c. } \quad 56 \text { above } \\
\quad \text { Mean } \\
\quad \text { Median } \\
\text { Range }\end{array}$ & $\begin{array}{c}0 \\
17 \\
13\end{array}$ & $\begin{array}{c}0 \\
56.67 \\
43.33 \\
\\
52.3 \\
54.5 \\
27.75\end{array}$ & $\begin{array}{c}0 \\
16 \\
14\end{array}$ & $\begin{array}{c}0 \\
53.33 \\
46.67 \\
\\
52.1 \\
52.5 \\
26.70\end{array}$ & $\begin{array}{c}\mathrm{t}=0.311 \mathrm{NS} \\
\mathrm{t}=0.42 \mathrm{NS}\end{array}$ \\
\hline
\end{tabular}




\begin{tabular}{|c|c|c|c|c|c|c|}
\hline 2 & $\begin{array}{c}\text { Marital Status } \\
\text { Married } \\
\text { Unmarried } \\
\end{array}$ & $\begin{array}{c}30 \\
0 \\
\end{array}$ & $\begin{array}{c}100 \\
0\end{array}$ & $\begin{array}{c}30 \\
0 \\
\end{array}$ & $\begin{array}{c}100 \\
0\end{array}$ & \\
\hline 3 & $\begin{array}{c}\text { Sex } \\
\text { a. Male } \\
\text { b. Female }\end{array}$ & $\begin{array}{c}27 \\
2\end{array}$ & $\begin{array}{l}90 \\
10\end{array}$ & $\begin{array}{c}30 \\
0\end{array}$ & $\begin{array}{c}100 \\
0\end{array}$ & $\begin{array}{c}\text { Chi }=3.16 \\
p>0.05 \mathrm{NS}\end{array}$ \\
\hline 4 & $\begin{array}{c}\text { Socio-Economic Status } \\
\text { Very low } \\
\text { Lower middle } \\
\text { Upper middle } \\
\text { High } \\
\text { Very High }\end{array}$ & $\begin{array}{c}0 \\
17 \\
12 \\
1 \\
0\end{array}$ & $\begin{array}{c}0 \\
56.7 \\
40.0 \\
3.3 \\
0\end{array}$ & $\begin{array}{c}0 \\
11 \\
19 \\
0 \\
0\end{array}$ & $\begin{array}{c}0 \\
36.7 \\
63.3 \\
0 \\
0\end{array}$ & $\begin{array}{c}\text { Chi } 4.371 \\
\mathrm{p}=5.99 \\
\text { NS }\end{array}$ \\
\hline 5 & $\begin{array}{l}\text { Literacy } \\
\text { a. Illiterate } \\
\text { b. Primary } \\
\text { c. High school } \\
\text { d. Higher education }\end{array}$ & $\begin{array}{c}9 \\
10 \\
5 \\
6 \\
\end{array}$ & $\begin{array}{l}30 \\
33 \\
17 \\
20 \\
\end{array}$ & $\begin{array}{c}8 \\
12 \\
7 \\
3 \\
\end{array}$ & $\begin{array}{c}26.67 \\
40 \\
23.33 \\
10 \\
\end{array}$ & $\begin{array}{l}\text { Chi }=1.57 \\
p>0.05 \mathrm{NS}\end{array}$ \\
\hline 6 & $\begin{array}{l}\text { Domicile } \\
\text { a. Urban } \\
\text { b. Rural }\end{array}$ & $\begin{array}{l}19 \\
11\end{array}$ & $\begin{array}{l}63 \\
37\end{array}$ & $\begin{array}{l}15 \\
15\end{array}$ & $\begin{array}{l}50 \\
50\end{array}$ & $\begin{array}{c}\text { Chi }=1.09 \\
p>0.05 \text { NS }\end{array}$ \\
\hline
\end{tabular}

\begin{tabular}{|c|c|c|c|c|c|}
\hline \multirow{2}{*}{$\begin{array}{c}\text { Clinical } \\
\text { Data }\end{array}$} & \multicolumn{2}{|c|}{$\begin{array}{c}\text { Sample } \\
\text { MI n=30 }\end{array}$} & \multicolumn{2}{c|}{$\begin{array}{c}\text { Control } \\
\text { D.M. }\end{array}$} & $\begin{array}{c}\text { Statistical } \\
\text { Significant }\end{array}$ \\
\cline { 2 - 6 } & Mean & S.D. & Mean & S. D. & \\
\hline $\begin{array}{c}\text { B.P. (mmHg) } \\
\text { Systolic }\end{array}$ & 131.3 & 23.06 & 115.7 & 18.40 & $\mathrm{t}=5.39 \mathrm{sig}$ \\
\hline Diastolic & 81.3 & 11.93 & 78.4 & 13.94 & $\mathrm{t}=3.35 \mathrm{sig}$ \\
\hline Blood Sugar & 102.4 & 11.71 & 236.7 & 24.59 & $\mathrm{t}=4.97 \mathrm{sig}$ \\
\hline $\begin{array}{c}\text { Sr. } \\
\text { Cholesterol }\end{array}$ & 174 & 29.2 & - & - & - \\
\hline \multicolumn{5}{c|}{$\begin{array}{c}\text { Table 2: Comparison of Clinical } \\
\text { Data between Sample and Control }\end{array}$} \\
\hline
\end{tabular}

\begin{tabular}{|c|c|c|c|c|c|}
\hline Clinical Date & \multicolumn{2}{|c|}{ Sample } & \multicolumn{2}{c|}{ Control } & $\begin{array}{c}\text { Statistical } \\
\text { significant }\end{array}$ \\
\hline $\begin{array}{c}\text { Alcohol } \\
\text { a. Absent }\end{array}$ & 18 & 60 & 21 & 70 & \\
\hline $\begin{array}{c}\text { b. Mild } \\
\text { (occasional) }\end{array}$ & 4 & 13.33 & 6 & 20 & Chi 3.04 \\
\hline $\begin{array}{c}\text { c. Moderate } \\
\text { 180 mL } \\
\text { twice or } \\
\text { thrice week }\end{array}$ & 6 & 20 & 2 & 6.67 & $\mathrm{p}>0.05 \mathrm{NS}$ \\
\hline $\begin{array}{c}\text { d. Heavy } \\
\text { (daily) }\end{array}$ & 2 & 6.67 & 1 & 3.33 & \\
\hline $\begin{array}{c}\text { Smoking } \\
\text { a) Absent }\end{array}$ & 14 & 46.67 & 14 & 46.67 & Chi $=0.52$ \\
\hline $\begin{array}{c}\text { b) Moderate } \\
<10 / \text { day }\end{array}$ & 10 & 33.33 & 8 & 26.67 & $\mathrm{p}>0.05$ \\
\hline $\begin{array}{c}\text { c) Severe } \\
>10 / \text { day }\end{array}$ & 6 & 20 & 8 & 26.7 & NS \\
\hline \multicolumn{7}{|c|}{$\begin{array}{l}\text { Table 3: Comparison of Clinical Data of Alcohol } \\
\text { and Smoking between Sample and Control }\end{array}$} \\
\hline
\end{tabular}

\begin{tabular}{|c|c|c|c|}
\hline & $\begin{array}{c}\text { More } \\
\text { Than 2 }\end{array}$ & $\begin{array}{c}\text { Less Than or } \\
\text { Equal to 2 }\end{array}$ & Total \\
\hline $\begin{array}{c}\text { Sample MI } \\
\mathrm{n}=30\end{array}$ & 17 & 13 & 30 \\
\hline $\begin{array}{c}\text { Control DM } \\
\mathrm{n}=30\end{array}$ & 6 & 24 & 30 \\
\hline Total & $\mathbf{2 3}$ & $\mathbf{3 7}$ & $\mathbf{6 0}$ \\
\hline $\begin{array}{c}\text { Table 4: Comparison of Number of Total Presumptive } \\
\text { Stressful Life Events (PSLE) between Sample and } \\
\text { Control }\end{array}$ \\
Chi 8.57 p <0.05 significant
\end{tabular}

Chi $8.57 \mathrm{p}<0.05$ significant

\begin{tabular}{|c|c|c|c|}
\hline & $\begin{array}{c}\text { More Than } \\
\mathbf{1 1 0}\end{array}$ & $\begin{array}{c}\text { Less Than or } \\
\text { Equal to 110 }\end{array}$ & Total \\
\hline Sample MI $\mathrm{n}=30$ & 21 & 9 & 30 \\
\hline Control DM $\mathrm{n}=30$ & 5 & 25 & 30 \\
\hline Total & $\mathbf{2 6}$ & $\mathbf{3 4}$ & $\mathbf{6 0}$ \\
\hline
\end{tabular}

Table 5: Comparison of Presumptive Stressful Life Events Score between Sample and Control

Chi $17.42 \mathrm{p}<0.05$ significant

\begin{tabular}{|c|c|c|c|c|}
\hline & Mild & Moderate & Nil & Total \\
\hline Sample MI $\mathrm{n}=30$ & 13 & 7 & 10 & 30 \\
\hline Control DM n=30 & 3 & 0 & 27 & 30 \\
\hline \multicolumn{5}{|c|}{$\begin{array}{r}\text { Table 6: Comparison of Depression } \\
\text { between Sample and Control }\end{array}$} \\
\hline
\end{tabular}

Chi 21.03 p=5.99 significant

\begin{tabular}{|c|c|c|c|}
\hline & \multicolumn{2}{|c|}{ Anxiety } & \multirow{2}{*}{ Total } \\
\cline { 2 - 3 } & Present & Absent & \\
\hline Sample MI n=30 & 10 & 20 & 30 \\
\hline Control DM n=30 & 5 & 25 & 30 \\
\hline \multicolumn{2}{|c|}{$\begin{array}{r}\text { Table 7: Comparison of Anxiety } \\
\text { between Sample and Control }\end{array}$} \\
\hline
\end{tabular}

Chi $=2.22 \mathrm{p}=3.84$ Not significant

\begin{tabular}{|c|c|c|c|c|}
\hline & $\begin{array}{c}\text { Total } \\
\text { PSLE } \\
\text { Score }\end{array}$ & Mean & SD & $\begin{array}{c}\text { Statistical } \\
\text { Significant }\end{array}$ \\
\cline { 1 - 3 } $\begin{array}{c}\text { Sample MI } \\
\mathrm{n}=30\end{array}$ & 4158 & 139 & 52.86 & $\begin{array}{c}\mathrm{t}=11.78 \\
\text { significant }\end{array}$ \\
\cline { 1 - 3 } $\begin{array}{c}\text { Control } \\
\text { DM n=30 }\end{array}$ & 2587 & 86 & 37.02 & \multicolumn{1}{|c|}{} \\
\cline { 1 - 3 } & &
\end{tabular}

Table 8: Comparison of Presumptive Stressful Life Events Score between Sample and Control

\begin{tabular}{|c|c|c|c|c|c|}
\hline \multirow{2}{*}{ Variable } & \multicolumn{2}{|c|}{$\begin{array}{c}\text { Sample MI } \\
\mathbf{n = 3 0}\end{array}$} & $\begin{array}{c}\text { Control DM } \\
\mathbf{n}=\mathbf{3 0}\end{array}$ & \multirow{2}{*}{$\begin{array}{c}\text { Statistical } \\
\text { Significant }\end{array}$} \\
\cline { 2 - 5 } & Mean & SD & Mean & SD & \\
\hline Anxiety & 5.13 & 4.23 & 3 & 3.86 & $\mathrm{t}=2.03 \mathrm{sig}$ \\
\hline Depression & 8.63 & 4.91 & 2.4 & 2.96 & $\mathrm{t}=5.93 \mathrm{sig}$ \\
\hline \multicolumn{3}{|c|}{ Table 9: Comparison of Anxiety and } \\
Depression Score Sample and Control \\
\hline
\end{tabular}




\begin{tabular}{|c|c|c|c|}
\hline \multirow{2}{*}{ Life events } & Hercentage & Total \\
\cline { 2 - 4 } & 8 & 8 & 16 \\
\hline$\leq 110$ & 1 & 13 & 14 \\
\hline$>110$ & 9 & 21 & 30 \\
\hline Total & Table 10: Comparison between Presumptive Life \\
Event Score and Hypertension in Sample & \\
\hline \multicolumn{2}{|c|}{} \\
\hline
\end{tabular}

Chi $6.52 \mathrm{p}<0.05$ significant

\begin{tabular}{|c|c|c|c|c|c|c|c|}
\hline & Age & Bp (s) & Bp (D) & Glu & L.E. & Anxi & Dep \\
\hline Age & 1.000 & & & & & & \\
\hline Bp (s) & -0.244 & 1.000 & & & & & \\
\hline Bp (D) & -0.042 & +0.579 & 1.000 & & & & \\
\hline Glu & -0.068 & -0.011 & +0.059 & 1.000 & & & \\
\hline L.E & -0.282 & +0.134 & +0.074 & +0.185 & 1.000 & & \\
\hline Anxi & -0.318 & +0.156 & +0.281 & +0.215 & +0.327 & 1.000 & \\
\hline Dep & +0.253 & -0.244 & -0.057 & -0.392 & -0.338 & -0.771 & 1.000 \\
\hline \multicolumn{7}{|l|}{ Table 11: Inter-Correlation Matrix for Selected Factors in Myocardial Infarction Group } \\
\hline
\end{tabular}

Anx - Anxiety, Dep - Depression, Bp(S) - Blood Pressure Systolic, Glu - Blood Glucose, Bp(D) - Blood Pressure Diastolic, L.E. - Life Events, + Positively Correlated, - Negative Correlated.

\begin{tabular}{|c|c|c|c|c|c|c|c|}
\hline & Age & Bp(s) & Bp(D) & Glu & L.E. & Anxi & Dep \\
\hline Age & 1.000 & & & & & & \\
\hline Bp(s) & -0.140 & 1.000 & & & & & \\
\hline Bp(D) & -0.119 & +0.848 & 1.000 & & & & \\
\hline Glu & -0.082 & +0.136 & +0.139 & 1.000 & & & \\
\hline L.E & -0.316 & +0.110 & +0.020 & -0.056 & 1.000 & & \\
\hline Anxi & -0.325 & +0.047 & -0.041 & -0.007 & -0.047 & 1.000 & \\
\hline Dep & -0.363 & -0.078 & -0.187 & -0.139 & +0.439 & -0.049 & 1000 \\
\hline \multicolumn{7}{|l}{ Table 12. Inter-Correlation Matrix for Selected Factors of Diabetes Mellitus Group } \\
\hline
\end{tabular}

Anx - Anxiety, Dep - Depression, Bp(S) - Blood Pressure Systolic, Glu - Blood Glucose, Bp(D) - Blood Pressure Diastolic, L.E. - Life Events, + Positively Correlated, - Negative Correlated

\section{DISCUSSION}

The findings in the study bring to light certain observations, which in spite of the limitations in the study, may be generalizable. The sample essentially consists of males and females in their middle ages or above, belonging to lower upper middle socio economic status predominantely, usually in the urban and rural domicile (Table 1). The higher incidence of myocardial infarction in the males and with the increasing age, have known biological variables and have been substantiated in many studies (WHO,19751; Bhatia et al 1990.13).

The hospital setting being free of cost, caters to relatively low socio economic population and the findings among the controls corroborates with the similar representation. Patients with myocardial infarction belong predominantly to the middle socio economic status. To interpret the finding as reflecting that myocardial infarction occurs in economically affluent population might have an element of fallacy. Patients with myocardial infarction might rush to the nearby hospital with all facilities available. The lack of significant number of patients belonging to the higher income group might reflect that those who could so afford probably gravitated to private hospitals. This may equally be the reason for the urban predominance in the infarction patients. The findings comparable to data of studies elsewhere in the west, which describes myocardial infarction as an urban phenomenon (Jatoo et al, 1988). ${ }^{3}$

Comparison of the clinical variables shows that infarction patients generally had a higher level of blood pressure (Table 2) It might indicate their proneness (WHO, 1975). ${ }^{1}$ All biochemical parameters could not be compared and findings are not significantly contributed.

Alcohol consumption was comparatively low among the myocardial infarction patients, because the alcohol population from a rural low socio economic background had an overwhelming presence of alcoholism (Table 3). Same could be the explanation for lesser incidence of smoking among the myocardial infarction patients.

Stressful life events (Tables 4 to 9) of two groups are compared. Both depression and anxiety were significantly more in myocardial infarction than the controls. The results compared with studies by Rahe (1971). ${ }^{25}$ Theorell et al (1993).22 and Mahendru et al (1976). ${ }^{14}$

We observed the significant life stresses are more in study patients. The common life stressors are going on pleasure trip (50.00\%), change in sleeping habit $(46.6 \%)$, death of a close family member (43.33\%), financial loss (36.66\%), large loan (33.33\%), self/family member unemployed (30.00\%), Illness of family members $(26.66 \%)$, change in residence $(25.66 \%)$, marriage of daughter/dependant sister (23.33\%), and conflict with the in-laws (20.00\%). Mahendru et al (1976) ${ }^{14}$ in their study had concluded that large number of patients $(61.8 \%)$ demonstrated emotional stress of significant intensity prior to the onset of myocardial infarction, while $38.2 \%$ did not experience such a stress. The most frequent areas of disturbance observed was maladjustment in the family (36.9\%), severe financial stress $(21.00 \%)$, job difficulties (19.7\%), heavy loss in business (19.7\%), heavy debts (15.7\%) marital disharmony (9.2\%), death of wife $(9.2 \%)$, maladjustment with other persons $(9.2 \%)$, law suits and court appearances (7.9\%), death of children (7.9\%). 
The death of close family members, illness in the family members, was the major contributors in the present study, whereas in the other maladjustment within the family members was the major contributor. Financial problems have been significantly present in both study groups. The difference in the perceived stresses could be well due to the sociocultural differences and perception of the different ethnic groups.

In the study, the significant life stressors is more in the family and social sphere, health sphere, and also in the work area. In the present study, 12 patients exhibited significant risk factors and the rest showed higher level of mean stressful scores. The perusal of the record shows that whenever infarction occurred without any risk factors, the stress score was high. The difference was statically significant.

Similarly, in the correlation matrix, stress was found to be positively correlating with blood pressure in the group and the control group. This might indicate that there could be a significant association between the perceived stress and cardiovascular response in the infarction patients and diabetes mellitus patients.

The limitation of the study is the small sample size. Also, it consists largely patients from middle socioeconomic status and so may affect the generalizability of the findings. It needs samples representing all socioeconomic status to have clear picture of the association of the biological and socioeconomic risk factors in coronary heart disease.

The main implication of the study is that psychological intervention particularly patient education, behaviour therapy likely to reduce stressfull life events and modify the disease outcome.

\section{REFERENCES}

1. World Health Organization. Official records of the World Health Organization. United Nations, World Health Organization Interim Commission 1975:227-228.

2. Chadha SL, Radhakrishna S, Ramachandran K, et al. Epidemiological study of CHD in an urban population. Indian Journal of Medical Research 1990;92:424-30.

3. Jajoo U, Kalantri SP, Gupta OP, et al. The prevalence of coronary heart disease in rural population from central India. JAPI 1988;36(12):689-690.

4. Friedman M, Rosenman RH. Overt behaviour pattern in coronary disease: detection of overt behaviour pattern a in patients with coronary disease by a new psychophysiological procedure. JAMA 1960;173(12):1320-5.

5. Kannel WB. Prevalence and natural history of electrocardiographic left ventricular hypertrophy. The American Journal of Medicine 1983;75(3):4-11.

6. Finegold JA, Asaria P, Francis DP. Mortality from ischaemic heart disease by country, region, and age: statistics from World Health Organisation and United Nations. International Journal of Cardiology 2013;168(2):934-45.

7. Friedman M, Rosenman RH. Association of specific overt behaviour pattern with blood and cardiovascular findings: blood cholesterol level, blood clotting time, incidence of arcus senilis, and clinical coronary artery disease. Journal of the American Medical Association 1959;169(12):1286-96.

8. Rosenman RH, Brand RJ, Jenkins D, et al. Coronary heart disease in the Western Collaborative Group Study. Final follow-up experience of $8 \quad 1 / 2$ years. JAMA 1975;233(8):872-7.
9. Haynes SG, Feinleib M, Kannel WB. The relationship of psychosocial factors to coronary heart disease in the Framingham study. III. Eight-year incidence of coronary heart disease. American Journal of Epidemiology 1980;111(1):37-58.

10. Kittel F, Kornitzer M, Dramaix M. Evaluation of type A personality. Postgraduate Medical Journal 1986;62(730):781-3.

11. Heller RF. Type A behaviour and coronary heart disease. Br Med J 1979;2(6186):368.

12. Shekelle RB, Hulley SB, Neaton JD, et al. The MRFIT behaviour pattern study II. Type A behaviour and incidence of coronary heart disease. American Journal of Epidemiology 1985;122(4):559-70.

13. Bhatia M, Tiwari A, Gupta H, et al. Type A behaviour, life events \& myocardial infarction. The Indian Journal of Medical Research 1990;92:95-100.

14. Mahendru RK, Sethi BB, Agrawal A. Psychological correlates in coronary heart disease. Indian Journal of Psychiatry 1976;18(4):273-82.

15. Reddy KR, Channabasavanna SM. Psycho social factors influencing the recovery after myocardial infarction. Indian journal of psychiatry 1987;29(2):155-59.

16. Andrews G. A prospective study of life events and psychological symptoms. Psychological Medicine 1981;11(4):795-801.

17. Krantz DS, Kop WJ, Santiago HT, et al. Mental stress as a trigger of myocardial ischemia and infarction. Cardiology Clinics 1996;14(2):271-87.

18. Shapiro PA. Psychiatric aspects of cardiovascular disease. Psychiatric Clinics of North America 1996;19(3):613-29.

19. Paykel ES. The Clinical Interview for Depression: development, reliability and validity. Journal of Affective Disorders 1985;9(1):85-96.

20. Jenkins CD. Recent evidence supporting psychologic and social risk factors for coronary disease. New England Journal of Medicine 1976;294(18):987-94.

21. Forrester AW, Lipsey JR, Teitelbaum ML, etal. Depression following myocardial infarction. The International Journal of Psychiatry in Medicine 1992;22(1):33-46.

22. Theorell T, Evy L, Jan FB, et al. A longitudinal study of 21 subjects with coronary heart disease: life changes, catecholamine excretion and related biochemical reactions. Psychosomatic Medicine 1972;34(6):505-16.

23. Lundberg $U$, Theorell $T$, Lind $E$. Life changes and myocardial infarction: individual differences in life change scaling. Journal of Psychosomatic Research 1975;19(1):27-32.

24. Ibrahim MA, Feldman JG, Sultz HA, et al. Management after myocardial infarction: a controlled trial of the effect of group psychotherapy. The International Journal of Psychiatry in Medicine 1974;5(3):253-68.

25. Rahe RH. Life change events and mental illness: an overview. Journal of Human Stress 1979;5(3):2-10.

26. Ruberman W, Weinblatt E, Goldberg JD, et al. Psychosocial influences on mortality after myocardial infarction. New England Journal of Medicine 1984;311(9):552-9.

27. Merz BCN, Dwyer J, Nordstrom CK, et al. Psychosocial stress and cardiovascular disease: pathophysiological links. Behavioural Medicine 2002;27(4):141-7. 
28. Singh G, Kaur D, Kaur H. Presumptive stressful life events scale (PSLES) - a new stressful life events scale for use in India. Indian Journal of Psychiatry 1984;26(2):107-14.

29. Holmes $\mathrm{TH}$, Rahe $\mathrm{RH}$. The social readjustment rating scale. Journal of Psychosomatic Research 1967;11(2):213-8.
30. Zigmond AS, Snaith RP. The hospital anxiety and depression scale. Acta Psychiatrica Scandinavica 1983;67(6):361-70.

31. Sharma R. Kuppuswamy's socioeconomic status scalerevision for 2011 and formula for real-time updating. Indian Journal of Paediatrics 2012;79(7):961-2. 